\title{
Configurações
}

Revista de sociologia

\section{Autonomização de jovens em acolhimento residencial: Discursos e significados}

Autonomy of youth in residential care: Speeches and meanings

Autonomie des jeunes en institution: Discours et significations

\section{Ana Daniela Silva, Kelly Oliveira e Cátia Marques}

\section{OpenEdition}

\section{Journals}

Edição electrónica

URL: http://journals.openedition.org/configuracoes/7305

DOI: $10.4000 /$ configuracoes.7305

ISSN: 2182-7419

\section{Editora}

Centro de Investigação em Ciências Sociais

Edição impressa

Paginação: 14-30

ISSN: 1646-5075

\section{Refêrencia eletrónica}

Ana Daniela Silva, Kelly Oliveira e Cátia Marques, « Autonomização de jovens em acolhimento residencial: Discursos e significados », Configurações [Online], 23 | 2019, posto online no dia 28 junho 2019, consultado o 30 junho 2019. URL : http://journals.openedition.org/configuracoes/7305 ; DOI : 10.4000/configuracoes.7305 
Silva, Ana Daniela; Oliveira, Kelly; Marques, Catia - Autonomização de jovens em acolhimento residencial: Discursos e significados. Configurações, vol. 23, 2019, pp. 14-30.

\title{
Autonomização de jovens em acolhimento residencial: Discursos e significados
}

\author{
ANA DANIELA SILVA* \\ Escola de Psicologia, Universidade do Minho, Braga, Portugal \\ KELLY OLIVEIRA** \\ Escola de Psicologia, Universidade do Minho, Braga, Portugal \\ CATIA MARQUES*** \\ Escola de Psicologia, Universidade do Minho, Braga, Portugal
}

\section{Resumo}

O acolhimento residencial de jovens ainda é uma medida de proteção bastante expressiva em Portugal sendo importante atender à construção dos seus projetos de vida. Neste estudo analisam-se discursos sobre percursos de carreira e vivência do processo de autonomização de sete jovens em acolhimento residencial, através da análise de conteúdo de uma entrevista sobre percursos e decisões escolares, experiência de acolhimento e processo de autonomização. Dos resultados sobressai a importância dada aos estudos nos percursos de carreira, aos sentimentos e às aprendizagens realizadas no acolhimento e às competências de adaptabilidade no processo de autonomização. Retiram-se implicações para a intervenção educativa e social com estes jovens.

Palavras-chave: Jovens em acolhimento residencial, carreira, acolhimento, autonomização.

\begin{abstract}

\footnotetext{
*E-mail: danielasilva@psi.uminho.pt

** E-mail:a68793@alunos.uminho.pt

***E-mail: catiamarques@psi.uminho.pt
}

Autonomy of youth in residential care: Speeches and meanings

The youth's residential care in Portugal is still a very significant protection measure and it is important to attend to the construction of their life projects. This study analyses speeches about career paths and the experience of the autonomization process of seven youths in residential care settings, through the content analysis of an interview about school paths and decisions, the reception experience and the process of autonomization. Results emphasized the importance given to studies in the career paths, to the feelings and learning carried on the residential care and to the competences of adaptability 
in the process of autonomization. Implications for educational and social intervention with these youths are drawn.

Keywords: Youth in residential care, career, residential care, independent-living.

\section{Résumé}

\section{Autonomie des jeunes en institution: Discours et significations}

L'accueil résidentiel des jeunes est encore une mesure de protection très expressive au Portugal, cause de ça il est important d'assister à la construction de leurs projets de vie. Cette étude analyse les discours sur les parcours professionnels et les expériences du processus d'autonomisation de sept jeunes en institution, à travers l'analyse du contenu d'un entretien sur les parcours et les décisions scolaires, l'expérience d'accueil et le processus d'autonomisation. Résultats, souligne l'importance accordée aux études dans les parcours professionnels, aux sentiments et à l'apprentissage réalisés dans l'accueil et aux compétences d'adaptabilité dans le processus d'autonomisation. Les implications pour l'intervention éducative et sociale auprès de ces jeunes sont dessinées.

Mots-clés: Jeunes en institution, carrière, accueil, autonomisation.

\section{Introdução}

Segundo a legislação portuguesa de Proteção de Crianças e Jovens em Perigo, o acolhimento residencial é uma medida que tem como finalidade proporcionar condições que garantam a adequada satisfação de necessidades físicas, psíquicas, emocionais e sociais das crianças e jovens e o efetivo exercício dos seus direitos, favorecendo a sua integração em contexto sociofamiliar seguro e promovendo a sua educação, bem-estar e desenvolvimento integral (Decreto Lei n ${ }^{\circ}$ 142/2015, de 8 de setembro da Proteção de Crianças e Jovens em Perigo, artigo n. ${ }^{\circ} 49$ ). A medida tem lugar em casas de acolhimento, e destina-se a crianças e jovens menores de 18 anos (ou menores de 21 anos desde que solicitem a continuação da intervenção iniciada antes de atingir os 18 anos, e ainda a menores de 25 anos sempre que existam, e apenas enquanto durem, processos educativos ou de formação profissional), em situação de perigo, a quem a Comissão de Proteção de Crianças e Jovens ou o Tribunal tenha aplicado uma medida de promoção e proteção de colocação em acolhimento residencial para os afastar da situação de perigo em que estes se encontravam (p. ex., negligência, maus tratos, abuso sexual).

Apesar do acolhimento residencial estar previsto nesta legislação, como a última medida a aplicar, esta é a que apresenta maior expressão em Portugal (Andrade, Santos, Costa e Sousa, 2014: 157-174) tornando o número de jovens em processo de institucionalização cada vez maior. Este facto torna-se claro quando comparamos o último relatório de Caracterização Anual da Situação de Acolhimento das Crianças e Jovens [CASA] de 2015 com os relatórios dos anos anteriores. Nessa comparação, podemos observar a tendência para um 
aumento de jovens em situação de acolhimento ao longo dos anos, verificando-se, em 2015, um aumento de jovens na faixa etária dos 15 aos 17 anos e dos 18 aos 20 anos. O mesmo relatório adianta que a autonomização é o projeto de vida relatado por estes jovens como mais importante (ISS, 2015). Neste sentido, o estudo dos significados de carreira em fase de autonomização destes jovens assume especial importância, de forma a proporcionar intervenções educativas e de carreira que favoreçam este processo. Por percursos de carreira entende-se um conjunto de vivências que se estendem ao longo de todo o ciclo vital e, nas quais o jovem deve integrar o trabalho, a família, o tempo livre, e a sua participação na comunidade, de forma a construir a sua vida (Silva, Coelho e Taveira, 2017: 171-181). A este respeito, verifica-se que a literatura sobre o impacto do acolhimento residencial nos percursos de carreira dos jovens tende a apontar uma trajetória menos positiva, bem como alguma falta de preparação das instituições para os acompanhar nesta transição de vida. Por exemplo, Carneiro (2005) refere que os jovens, de um modo global, abandonam as instituições de acolhimento quando atingem a maioridade e não possuem as competências necessárias para se enquadrarem na sociedade. Segundo o autor, esta falta de competências sociais e de autonomização refletem-se de forma menos positiva a nível pessoal, profissional e familiar. O estudo de Ribeiro (2008: 1-56) debruçou-se sobre as dificuldades de autonomização destes jovens, investindo na promoção de competências pessoais e sociais que favoreçam a autonomia dos jovens, bem como na formação especializada dos técnicos que trabalham diretamente com esta população. De igual modo Costa, Tomás, Luís, Rodrigues, Malheiro e Gonçalves (2015) apresentam uma proposta para trabalhar a autonomia de jovens em acolhimento residencial, concluindo que desenvolver a autonomia, implica por um lado que esta seja internalizada por cada um dos jovens e, por outro, que as equipas da casa de acolhimento sejam capazes de potenciar essa mesma autonomia.

Este apoio visa fomentar aprendizagens tais como a gestão financeira e doméstica, a procura de emprego, entre outras (Silva, Araújo e Taveira 2011; Gonçalves, 2013). Com efeito, o apoio dado a esta população deve ir para além da mera informação, sendo necessários apoios à formação quer na procura de casa e emprego, ligação com a família e procura de recursos ou sistemas de apoio que os protejam e salvaguardem transitoriamente em potenciais situações de risco, tais como um primeiro desemprego (Courtney, Piliavin, Grogan-Kraylor e Nesmith, 2001; Forsman e Vinnerljung, 2012). Santos (2010), também antecipa trajetórias de carreira menos positivas, marcadas por constrangimentos motivacionais, onde predominam o desinteresse e o absentismo escolar dos jovens. Segundo estes autores são poucos os jovens em acolhimento residencial que prosseguem estudos, podendo isto dever-se a razões económicas, organizacionais ou familiares. As expectativas e ambições destes jovens centram-se sobretudo em ter uma casa, constituir família e conseguirem 
uma vida sustentável (Courtney, Piliavin, Grogan-Kaylor e Nesmith, 2001; Forsman e Vinnerljung, 2012).

Ainda que menos expressiva, também é de referir uma outra vertente da literatura que se foca nos aspetos protetores do acolhimento residencial. Esta literatura tende a enfatizar a organização proporcionada pelo acolhimento que, em situações de vulnerabilidade, podem favorecer o desenvolvimento humano, podendo constituir uma fonte de apoio social organizada para lidar com as adversidades (Santos e Bastos, 2002; Siqueira e Dell 'Aglio, 2006)

A este respeito, Garmezy, Masten e Tellenge (1984) referem que o bom desempenho escolar e nível intelectual podem operar como fatores de proteção e diminuir os efeitos do stress que a vivência em acolhimento residencial pode causar, promovendo a resiliência dos jovens. De acordo com a teoria da resiliência, Fergus e Zimmerman (2005) referem que algumas pessoas conseguem superar adversidades na vida mesmo estando expostas a situações de risco, conseguindo resultados positivos e inesperados. Com o objetivo de especificar os domínios particulares da resiliência, os investigadores começaram a usar o termo "resiliência educacional" (Wang e Gordon, 1994: 1), definindo-a como a "probabilidade do sucesso escolar, apesar das adversidades ambientais, provocadas por traços iniciais, condições e experiências”. Também Rodrigues (2016: 67) se refere ao acolhimento residencial como sendo visto pelos jovens como uma oportunidade de vida, respeitando os direitos, fornecendo um acolhimento personalizado e assentando no desenvolvimento e bem-estar educacional e afetivo dos jovens.

A revisão da literatura a este respeito parece, então, apontar para a importância de estudar o acolhimento residencial não como uma condição de fracasso na carreira ou má preparação para a vida autónoma, mas sim como um todo, tendo ciente o facto de existirem diversos fatores, tanto individuais como ambientais, que condicionam o seu percurso de carreira e processo de autonomização. Neste sentido, torna-se pertinente explorar estes percursos partindo dos significados que os jovens lhes atribuem e tentando identificar aspetos protetores e de risco destas trajetórias. Um estudo do ISS (2005) seguiu esta linha, elaborando um conjunto de propostas para intervenção com jovens em acolhimento residencial, a partir do discurso dos mesmos. Neste trabalho, o ISS (2005) propõe como uma das medidas de intervenção o processo de autonomização, apelando para que este seja preparado no momento da entrada da criança, bem como num trabalho contínuo com a família. Em continuação com esta linha de trabalho, este estudo pretende analisar a perceção que os jovens em acolhimento residencial têm acerca dos seus percursos de carreira e vivência do processo de autonomização. Através desta análise de conteúdo dos discursos dos/as jovens, procuramos compreender o que os jovens consideram importante para uma adaptação à vida autónoma, podendo também servir 
de base teórica para uma melhoria na intervenção social e educativa com esta população.

\section{Método}

\subsection{Participantes}

A população deste estudo inclui jovens em situação de acolhimento residencial em fase de autonomização, ou seja, acima dos 17 anos de idade, de duas instituições do distrito de Braga. A amostra é constituída por seis raparigas $(85,71 \%)$ e um rapaz (14,9\%) com idades entre os 17 e 19 anos (Midade=17.71, $\mathrm{DP}=0.76)$. Todos tem nacionalidade portuguesa, sendo que duas jovens tem dupla nacionalidade: francesa e portuguesa e, brasileira e portuguesa. O tempo de vivência em acolhimento residencial era, em média, de 4,4 anos, variando entre um máximo de 8 anos e um mínimo de 10 meses. Quanto ao nível de escolaridade, uma jovem frequentava o $8 .^{\circ}$ ano, outra o $9 .^{\circ}$ ano, outra o $10 . .^{\circ}$ ano, duas delas frequentavam o $11 .^{\circ}$ ano, o jovem frequentava o $12 .^{\circ}$ ano e uma jovem estava no $1 .^{\circ}$ ano de universidade.

\subsection{Instrumentos}

Os/as participantes responderam a um questionário sociodemográfico que incluía questões relativas ao sexo, idade, nacionalidade, tempo de vivência em acolhimento residencial e escolaridade. Para além deste instrumento, os/as participantes responderam também ao guião de uma entrevista semiestruturada sobre os seus percursos de carreira. Trata-se de um guião composto por onze questões que analisam três dimensões destes percursos: a perceção dos percursos e decisões escolares, a perceção da experiência de acolhimento e a perceção do processo de autonomização. De forma a analisarmos a perceção dos/ as jovens relativamente aos seus percursos e decisões escolares incidimos sobre temas como o rendimento escolar, o processo de tomada de decisão escolar e a exploração vocacional. Para tal, foram feitas as seguintes questões: "Como carateriza o seu percurso de carreira até ao momento?", "Como foi tomando as suas decisões ao longo desse percurso?" e "Que decisões acha que foram as mais importantes?”. Quanto à perceção da experiência de acolhimento, foram analisados os sentimentos associados à vivência em acolhimento, à situação em si e às pessoas envolvidas, aos pensamentos e comportamentos associados e às aprendizagens feitas no contexto de acolhimento. Desta forma, questionou-se os/as jovens acerca de experiências que viveram em Acolhimento Residencial e o significado que estas tinham tido para eles: "Durante a sua vivência em Acolhimento Residencial, certamente viveu muitas experiências. Recorde um acontecimento ou episódio que seja o mais significativo? Aquele acontecimento que acha que nunca vai esquecer? Pode descrever e explicar porque foi importante para si?". E, por último, de forma a compreender como os jovens 
percecionam o processo de autonomização, foi questionado todo o processo de preparação para a saída do acolhimento, os objetivos a nível pessoal e profissional, as barreiras antecipadas, os apoios percecionados pelos jovens para esta fase, tal como recursos materiais e suporte social, bem como o nível de comprometimento com os objetivos estabelecidos: "Em que momento começou a preparar-se para sair do Lar? Como foi fazendo a sua preparação para a saída do Lar? Que pensamentos teve em relação a isto? Como se sentiu? Como reagiu ao longo desse processo?”, “Quem foram as pessoas que mais o ajudaram neste processo?”, “Que objetivos tem para o futuro? A nível profissional e pessoal?”, "Que dificuldades acha que pode encontrar nos próximos anos? O que acha que vai ser mais difícil? Em que áreas de vida?”, "Como acha que as poderá ultrapassar?", "O que está disposto a ceder, e a fazer para alcançar os seus objetivos?", "Qual o lema de vida que pensa seguir ao longo da sua vida? Que valores lhe estão associados ou considera mais importante seguir?" e "Que conselho daria a um jovem mais novo que esteja a viver em lar, tendo em vista a sua preparação para a vida adulta independente do lar?”.

\subsection{Procedimentos}

$\mathrm{Na}$ constituição do grupo de sujeitos para a investigação, procedeu-se a uma recolha de amostra de conveniência a jovens em acolhimento residencial com mais de 17 anos.

Para tal, contactou-se duas casas de acolhimento do distrito de Braga e, após autorização por parte destas entidades e dos/as jovens participantes, procedeu-se à recolha de dados. A recolha decorreu, num único momento, em entrevistas individuais, com a duração aproximada de uma hora cada uma. Estas entrevistas decorreram numa sala de estudo da residência de acolhimento. Neste contexto, foi entregue a cada participante no estudo um consentimento informado, sob forma escrita, sendo reforçada a voluntariedade e confidencialidade das respostas, salientando-se a inexistência de respostas corretas ou erradas. Foi também pedida autorização para gravação áudio das entrevistas. Em seguida, foi administrado o questionário sociodemográfico e, no que concerne a este, foi colocado um código, que permite a correspondência entre estes dados e os dados da entrevista. A entrevista foi gravada em áudio de forma a facilitar a interação característica de uma entrevista semiestruturada, de modo a evitar perda de dados. Posteriormente procedeu-se à transcrição das entrevistas.

\subsection{Análise}

A análise qualitativa dos discursos dos/as jovens recorreu aos procedimentos da análise de conteúdo expostos por Bardin (2013), sendo analisadas as 136 respostas dadas pelos/as participantes. A opção por esta metodologia qualitativa exploratória tem como objetivo identificar categorias de significado 
que caracterizem os discursos dos/as jovens em acolhimento quanto aos seus percursos de carreira e vivência do processo de autonomização.

Durante a análise, todos os elementos foram tidos em consideração, sem exclusões, sendo que nenhum sujeito ou documento transcrito foram retirados da análise. Numa primeira fase, foi elaborada uma pré-análise, que consistiu numa leitura flutuante da transcrição das entrevistas. Esta leitura tem como objetivo conhecer o texto a analisar para organizar de forma não estruturada aspetos importantes para as próximas fases da análise. Na segunda fase, de exploração do material, procedeu-se à codificação. Para tal, foram utilizados procedimentos tais como o recorte, a agregação, e a enumeração, de forma a alcançar uma representação exata do seu conteúdo. A cada participante foi atribuído a letra S (sujeito) e um número (de 001 a 007). Como unidade de contexto, considerou-se as respostas dos sujeitos às questões colocadas ao longo da entrevista, e como unidade de análise, foi considerada a ideia, sendo que tanto à unidade de contexto como à unidade de análise foi atribuído um número. A regra de enumeração utilizada foi a regra de frequência (Bardin, 2013: 134). Foi ainda realizada uma análise temática, de forma a alcançar núcleos de sentido, em que, para cada unidade de contexto (resposta às questões) foram recortadas as várias unidades de análise (ideias), sendo posteriormente agrupadas em categorias de análise temáticas, ou seja, em “ núcleos de registo ”. Como resultado desta análise, emergiram categorias de significado que possibilitaram a agregação e classificação das unidades de análise. Foram identificadas 136 unidades de contexto correspondente a 162 unidades de análise, emergindo um total de 31 unidades de significado.

O critério de categorização utilizado foi um critério semântico, em que todas as ideias associadas a um dado foram agrupadas numa mesma categoria de sentido. As categorias selecionadas tiveram em consideração os seguintes critérios: exclusão mútua, pertinência, homogeneidade, objetividade e fidelidade, e produtividade. A realização da análise de conteúdo foi feita manualmente.

\section{Resultados}

Os quadros 1, 2 e 3 apresentam um total de 15 categorias e respetivas subcategorias identificadas, os respetivos núcleos de sentido e a frequência total de cada categoria. No quadro 1, referente aos fatores mencionados pelos jovens acerca dos percursos de carreira, a categoria mais referida $(n=12) \mathrm{diz}$ respeito ao papel dos estudos, mais concretamente na relação com o curso/estágio, onde os/as jovens referem sentimentos, expetativas e indecisões em relação aos percursos académicos. No que se refere ao segundo quadro, ou seja, aos fatores mencionados pelos/as jovens na experiência de acolhimento, o discurso dos/as jovens baseou-se sobretudo nas categorias relacionadas com os sentimentos experienciados tanto à entrada como no decorrer da sua vivência em 
acolhimento residencial ( $n=7)$, com as aprendizagens/perceções acerca da sua vivência em acolhimento $(\mathrm{n}=5)$ e com as memórias no acolhimento relacionadas com as interações familiares $(n=7)$. Por último, no quadro 3, referente aos fatores mencionados no processo de autonomização, destaca-se a subcategoria competências de adaptabilidade $(\mathrm{n}=15)$, que consiste na capacidade do/a jovem gerar alternativas perante adversidades e/ou abdicar de determinados aspetos em prol dos seus objetivos (ver quadros). 


\section{Quadro 1. Fatores mencionados nos percursos de carreira}

\begin{tabular}{|c|c|c|c|c|}
\hline Categorias & $\begin{array}{l}\text { Subcatego- } \\
\text { rias }\end{array}$ & $\begin{array}{l}\text { Descrição/Núcleo } \\
\text { de Sentido }\end{array}$ & Freq. & Exemplos \\
\hline $\begin{array}{l}\text { Alternativas } \\
\text { de escolha de } \\
\text { carreira }\end{array}$ & \multicolumn{2}{|c|}{$\begin{array}{l}\text { Refere-se à diversidade/escassez } \\
\text { de alternativas/opções apresenta- } \\
\text { das e à ideia do sujeito ter certe- } \\
\text { zas/confusão, a nível das alterna- } \\
\text { tivas de carreira. }\end{array}$} & 5 & $\begin{array}{l}\text { "quando fiz os testes voca- } \\
\text { cionais nunca ninguém me } \\
\text { pôs a hipótese de ir para } \\
\text { o regular, nem eu pus essa } \\
\text { hipótese" (S006_005_006) }\end{array}$ \\
\hline $\begin{array}{l}\text { Autonomia } \\
\text { nas decisões } \\
\text { escolares }\end{array}$ & \multicolumn{2}{|c|}{$\begin{array}{l}\text { Refere-se à ideia do sujeito ter } \\
\text { autonomia nas decisões escolares } \\
\text { ou o sujeito ser influenciado pe- } \\
\text { los outros, ou as decisões serem } \\
\text { tomadas por razões de perspetiva } \\
\text { temporal. }\end{array}$} & 6 & $\begin{array}{l}\text { "eu optei por essa escola } \\
\text { pelas boas recomendações } \\
\text { que ouvia dos profes- } \\
\text { sores que lecionavam" } \\
\text { (S002_002_004) }\end{array}$ \\
\hline $\begin{array}{l}\text { Motivos de } \\
\text { escolha da } \\
\text { área/curso } \\
\text { atual }\end{array}$ & \multicolumn{2}{|c|}{$\begin{array}{l}\text { Refere-se à razão/motivação do } \\
\text { sujeito para a escolha da área/ } \\
\text { curso atual. }\end{array}$} & 5 & $\begin{array}{l}\text { "humanidades é onde eu } \\
\text { me revejo porque gosto } \\
\text { muito de português e } \\
\text { historia e como eu tinha } \\
\text { a ideia de ir para direito } \\
\text { foi uma escolha simples" } \\
\text { (SO02_002_003) }\end{array}$ \\
\hline \multirow{5}{*}{$\begin{array}{l}\text { Papel dos es- } \\
\text { tudos }\end{array}$} & \multicolumn{4}{|c|}{$\begin{array}{l}\text { Refere-se ao papel dos estudos para os percursos de carreira dos jovens, } \\
\text { incluindo aspetos como o rendimento escolar, aspirações escolares, a sua } \\
\text { relação com o curso atual/estágio em que se encontra e a forma como se } \\
\text { relaciona com a escola }\end{array}$} \\
\hline & $\begin{array}{l}\text { Rendimen- } \\
\text { to escolar }\end{array}$ & $\begin{array}{l}\text { Refere-se a aspetos } \\
\text { relacionados com o } \\
\text { rendimento escolar }\end{array}$ & 4 & $\begin{array}{l}\text { "para já a média que } \\
\text { tenho é me favorável” } \\
(\mathrm{S} 002 \text { 002_006) }\end{array}$ \\
\hline & $\begin{array}{l}\text { Aspirações } \\
\text { escolares }\end{array}$ & $\begin{array}{l}\text { Refere-se ao desejo } \\
\text { em continuar os es- } \\
\text { tudos }\end{array}$ & 9 & $\begin{array}{l}\text { "eu queria tirar mecâni- } \\
\text { ca de automóveis depois" } \\
\text { (S005_002_002) }\end{array}$ \\
\hline & $\begin{array}{l}\text { R e } 1 \text { a ç ã o } \\
\text { com o cur- } \\
\text { so/estágio }\end{array}$ & $\begin{array}{l}\text { Refere-se a senti- } \\
\text { mentos, expetati- } \\
\text { vas e indecisões em } \\
\text { relação ao estágio/ } \\
\text { curso. }\end{array}$ & 12 & $\begin{array}{l}\text { "acho que o curso que é } \\
\text { perfeito para mim, tem } \\
\text { desenho e eu adoro" } \\
\text { (S003_003_003) }\end{array}$ \\
\hline & $\begin{array}{l}\text { R e } 1 \text { a ç ã o } \\
\text { com a es- } \\
\text { cola }\end{array}$ & $\begin{array}{l}\text { Refere-se aos senti- } \\
\text { mentos de interesse } \\
\text { e/ou importância } \\
\text { dada à escola. }\end{array}$ & 6 & $\begin{array}{l}\text { "não acho que a escola } \\
\text { seja importante, mas sei } \\
\text { que é obrigatório fazer" } \\
\text { (S005_025_025) }\end{array}$ \\
\hline $\begin{array}{l}\text { Pessoas sig- } \\
\text { nificativas } \\
\text { nos percur- } \\
\text { sos }\end{array}$ & \multicolumn{2}{|c|}{$\begin{array}{l}\text { Refere-se às pessoas particular- } \\
\text { mente importantes ou significati- } \\
\text { vas na vida do jovem, pelas fun- } \\
\text { ções ou papéis que desempenham. }\end{array}$} & 7 & $\begin{array}{l}\text { "o meu melhor amigo (...) } \\
\text { ele é tipo a minha alma } \\
\text { gémea, ele dá conselhos, é } \\
\text { compreensivo, é extrover- } \\
\text { tido, é assim uma pessoa } \\
\text { que me inspira mesmo" } \\
\text { (S005_018_018) }\end{array}$ \\
\hline
\end{tabular}




\begin{tabular}{|c|c|c|c|c|}
\hline \multirow{4}{*}{$\begin{array}{l}\text { Valores de } \\
\text { vida }\end{array}$} & \multicolumn{4}{|c|}{$\begin{array}{l}\text { Diz respeito aos valores que os jovens considera importantes seguir como } \\
\text { lema de vida. }\end{array}$} \\
\hline & $\begin{array}{l}\text { Focados no } \\
\text { prazer }\end{array}$ & $\begin{array}{l}\text { Refere-se a carate- } \\
\text { rísticas hedonistas } \\
\text { como aproveitar a } \\
\text { vida ou obtenção } \\
\text { de prazer imediato. }\end{array}$ & 2 & $\begin{array}{l}\text { "eu acho que se deve fa- } \\
\text { zer sempre o que se gosta" } \\
\text { (S002_001_002) }\end{array}$ \\
\hline & $\begin{array}{l}\text { Focados no } \\
\text { esforço pes- } \\
\text { soal }\end{array}$ & $\begin{array}{l}\text { Refere-se a carate- } \\
\text { rísticas que incluem } \\
\text { esforço e trabalho } \\
\text { e/ou entrega pes- } \\
\text { soal como lema de } \\
\text { vida. }\end{array}$ & 5 & $\begin{array}{l}\text { "é importante todos nós lu- } \\
\text { tarmos por aquilo que que- } \\
\text { remos e fazer valer o nosso } \\
\text { esforço" (SO04_018_021) }\end{array}$ \\
\hline & $\begin{array}{l}\text { Focados em } \\
\text { atitudes }\end{array}$ & $\begin{array}{l}\text { Refere-se a atitudes } \\
\text { a adotar na vida } \\
\text { tais como genuini- } \\
\text { dade e liberdade. }\end{array}$ & 2 & $\begin{array}{l}\text { "seguir o que elas acham } \\
\text { que está certo e não pen- } \\
\text { sar nas criticas que as } \\
\text { outras pessoas dizem" } \\
\text { (S006_022_026) }\end{array}$ \\
\hline
\end{tabular}

Quadro 2. Fatores mencionados na experiência de acolhimento

\begin{tabular}{|c|c|c|c|c|}
\hline Categorias & Subcategorias & $\begin{array}{l}\text { Descrição/ } \\
\text { Núcleo de } \\
\text { Sentido }\end{array}$ & Freq & Exemplos \\
\hline Sentimentos & \multicolumn{2}{|c|}{$\begin{array}{l}\text { Refere-se aos sentimentos experienciados } \\
\text { pelo sujeito tanto à entrada como no de- } \\
\text { correr da sua vivência em acolhimento re- } \\
\text { sidencial }\end{array}$} & 7 & $\begin{array}{l}\text { "aqui sinto-me muito pre- } \\
\text { sa e farta de estar aqui" } \\
\text { (S003_017_019) }\end{array}$ \\
\hline Pensamentos & \multicolumn{2}{|c|}{$\begin{array}{l}\text { Refere-se aos pensamentos do sujeito duran- } \\
\text { te a sua vivência em acolhimento residencial }\end{array}$} & 2 & $\begin{array}{l}\text { "tu pensas que vais encontrar } \\
\text { algo pior que o que esperas." } \\
\text { (S002_003_007) }\end{array}$ \\
\hline Aprendizagens & \multicolumn{2}{|c|}{$\begin{array}{l}\text { Refere-se às aprendizagens/perceções do su- } \\
\text { jeito acerca da sua vivência em acolhimento. }\end{array}$} & 5 & $\begin{array}{l}\text { "eu acho que o facto de eu ter } \\
\text { vindo para a instituição fez } \\
\text { com que os meus horizontes e } \\
\text { objetivos fossem mais claros" } \\
\text { (S002_008_019) }\end{array}$ \\
\hline \multirow[t]{4}{*}{$\begin{array}{l}\text { Memórias no } \\
\text { acolhimento }\end{array}$} & \multicolumn{4}{|c|}{$\begin{array}{l}\text { Refere-se a memórias relacionadas com episódios significativos da vivência em acolhi- } \\
\text { mento. }\end{array}$} \\
\hline & Chegada à instituição & $\begin{array}{l}\text { Refere-se a } \\
\mathrm{m} \text { e m ó } \mathrm{r} \text { i a s } \\
\text { que retratem } \\
\text { os primeiros } \\
\text { dias em aco- } \\
\text { lhimento resi- } \\
\text { dencial. }\end{array}$ & 2 & $\begin{array}{l}\text { "o que mais me marcou foi } \\
\text { o dia que entrei para cá” } \\
\text { (S002_003_009) }\end{array}$ \\
\hline & Interações com familiares & $\begin{array}{l}\text { Refere-se às } \\
\text { visitas e/ou } \\
\text { acontecimen- } \\
\text { tos de vida de } \\
\text { familiares. }\end{array}$ & 4 & $\begin{array}{l}\text { "e quando os meus dois irmãos } \\
\text { novos foram adotados, acho } \\
\text { que esse foi o momento mais } \\
\text { marcante" (S006_006_007) }\end{array}$ \\
\hline & Sucessos académicos & $\begin{array}{l}\text { Refere-se ao } \\
\text { alcance de ob- } \\
\text { jetivos a nível } \\
\text { escolar. }\end{array}$ & 1 & $\begin{array}{l}\text { "o momento assim mais mar- } \\
\text { cante foi quando soube que } \\
\text { tinha entrado para a universi- } \\
\text { dade" (S004_005_006) }\end{array}$ \\
\hline
\end{tabular}




\section{Quadro 3. Fatores mencionados no processo de autonomização}

\begin{tabular}{|c|c|c|c|c|c|}
\hline Categorias & Subcategorias & \multicolumn{2}{|c|}{ Descrição/Núcleo de Sentido } & Freq & Exemplos \\
\hline Sentimentos & \multicolumn{3}{|c|}{$\begin{array}{l}\text { Refere-se aos sentimentos experienciados pelo sujeito } \\
\text { acerca da sua saída do acolhimento residencial. }\end{array}$} & 6 & $\begin{array}{l}\text { "sinto que ainda não estou preparada, } \\
\text { sinto que ainda me falta alguma coisa" } \\
\text { (S006_009_010) }\end{array}$ \\
\hline Pensamentos & \multicolumn{3}{|c|}{$\begin{array}{l}\text { Refere-se aos pensamentos acerca da sua saída do acolhi- } \\
\text { mento residencial. Incluindo o desejo e motivos relaciona- } \\
\text { dos com a sua saída. }\end{array}$} & 8 & $\begin{array}{l}\text { "penso em sair daqui todos os dias pratica- } \\
\text { mente" (S001_015_017) }\end{array}$ \\
\hline \multirow{3}{*}{$\begin{array}{l}\text { Planeamento } \\
\text { da saída do } \\
\text { Acolhimento }\end{array}$} & \multicolumn{5}{|c|}{ Diz respeito à perspetiva temporal, e às expectativas de futuro. Expressa a ideia de construção do futuro. } \\
\hline & Momento & $\begin{array}{l}\text { Refere-se ao planear } \\
\text { mento da saída do ac }\end{array}$ & $\begin{array}{l}\text { nto do mo- } \\
\text { himento. }\end{array}$ & 2 & $\begin{array}{l}\text { "principalmente eu gostava de ir embora } \\
\text { quando acabar o curso, principalmente é } \\
\text { esta a ideia" (S007_006_007) }\end{array}$ \\
\hline & Aspirações & $\begin{array}{l}\text { Refere-se às aspiraçõ } \\
\text { do sair do acolhimen }\end{array}$ & para quan- & 8 & $\begin{array}{l}\text { "quero continuar a estudar e vou ver se } \\
\text { consigo arranjar um part-time, para ver se } \\
\text { junto dinheiro para conseguir entrar para } \\
\text { a universidade e para ajudar a minha mãe" } \\
\text { (S006_013_014) }\end{array}$ \\
\hline \multirow{4}{*}{$\begin{array}{l}\text { Dificuldades } \\
\text { perceciona- } \\
\text { das }\end{array}$} & \multicolumn{5}{|c|}{ Refere-se às dificuldades/barreiras que o jovem espera encontrar quando sair do acolhimento. } \\
\hline & $\begin{array}{l}\text { Dificuldades inter- } \\
\text { pessoais }\end{array}$ & \multicolumn{2}{|c|}{$\begin{array}{l}\text { Refere-se às dificuldades/barreiras } \\
\text { interpessoais que quando sair do } \\
\text { acolhimento. }\end{array}$} & 1 & $\begin{array}{l}\text { "conviver com pessoas e falar com pessoas } \\
\text { que eu já conhecia” (S001_019_021) }\end{array}$ \\
\hline & $\begin{array}{l}\text { Dificuldades em ta- } \\
\text { refas autónomas }\end{array}$ & \multicolumn{2}{|c|}{$\begin{array}{l}\text { Refere-se às dificuldades em rea- } \\
\text { lizar tarefas de forma autónoma } \\
\text { quando sair do acolhimento. }\end{array}$} & 3 & $\begin{array}{l}\text { "lá fora acho que a minha mãe não vai an- } \\
\text { dar tão em cima de mim como estão aqui, } \\
\text { tenho medo de me perder" (S006_010_011) }\end{array}$ \\
\hline & $\begin{array}{l}\text { Dificuldades de es- } \\
\text { tágio/emprego }\end{array}$ & \multicolumn{2}{|c|}{$\begin{array}{l}\text { Refere-se às dificuldades em encon- } \\
\text { trar estágio/emprego quando sair } \\
\text { do acolhimento. }\end{array}$} & 4 & $\begin{array}{c}\text { "é difícil encontrar trabalho" } \\
(\text { S005_019_019) }\end{array}$ \\
\hline \multirow[t]{9}{*}{ Recursos } & \multicolumn{5}{|c|}{ Incluí a referência a meios de auxílio no processo de autonomização. } \\
\hline & $\begin{array}{l}\text { Figuras de suporte } \\
\text { social }\end{array}$ & \multicolumn{4}{|c|}{$\begin{array}{l}\text { Refere-se à importância de várias figuras que oferecem suporte social, apoiando emocional, infor- } \\
\text { macional e/ou instrumentalmente o jovem no seu processo de autonomização. }\end{array}$} \\
\hline & & Família & $\begin{array}{l}\text { Refere-se } \\
\text { à perceção } \\
\text { do apoio da } \\
\text { família }\end{array}$ & 9 & $\begin{array}{l}\text { "a minha irmã e o meu pai poderiam ajudar-me" } \\
\text { (S001_025_027) }\end{array}$ \\
\hline & & Amigos & $\begin{array}{l}\text { Refere-se à } \\
\text { perceção do } \\
\text { apoio dos } \\
\text { amigos }\end{array}$ & 3 & $\begin{array}{l}\text { "estou a contar com a ajuda da minha melhor } \\
\text { amiga que ela está na minha turma e ela é apli- } \\
\text { cada" (S006_011_012) }\end{array}$ \\
\hline & & Técnicos/cuidadores & $\begin{array}{l}\text { Refere-se à } \\
\text { perceção do } \\
\text { apoio dos } \\
\text { técnicos }\end{array}$ & 4 & $\begin{array}{l}\text { " "as doutoras incentivam a ter uma vida me- } \\
\text { lhor" (S004_013_016) }\end{array}$ \\
\hline & $\begin{array}{l}\text { Ausência de figuras } \\
\text { de suporte social }\end{array}$ & \multicolumn{2}{|c|}{$\begin{array}{l}\text { Refere-se à ausência de figuras de } \\
\text { suporte social no apoio à de autono- } \\
\text { mização. }\end{array}$} & 6 & $\begin{array}{l}\text { "só posso contar comigo própria" } \\
(\text { S005_015_015) }\end{array}$ \\
\hline & Apoios estatais & \multicolumn{2}{|c|}{$\begin{array}{l}\text { Refere-se aos apoios estatais na auto- } \\
\text { nomização. }\end{array}$} & 2 & $\begin{array}{l}\text { "acho que os apoios estatais e o meu pai seria } \\
\text { à partida a forma onde primeiro iria recorrer" } \\
\text { (S002_009_021) }\end{array}$ \\
\hline & Meios & \multicolumn{2}{|c|}{$\begin{array}{l}\text { Refere-se aos meios utilizados pelo } \\
\text { jovem para a autonomização. }\end{array}$} & 8 & $\begin{array}{l}\text { "já enviei currículos, já me inscrevi na net em } \\
\text { novos anúncios" (S004_016_019) }\end{array}$ \\
\hline & $\begin{array}{l}\text { Competências de } \\
\text { adaptabilidade }\end{array}$ & \multicolumn{2}{|c|}{$\begin{array}{l}\text { Refere-se à capacidade do jovem a } \\
\text { gerar alternativas perante adversida- } \\
\text { des e/ou abdicar de determinados as- } \\
\text { petos em prol dos seus objetivos. }\end{array}$} & 15 & $\begin{array}{l}\text { "se não tiver média fico a trabalhar, arranjo } \\
\text { um emprego e preparo-me para entrar no ano } \\
\text { seguinte" (S003_004_005) }\end{array}$ \\
\hline
\end{tabular}




\section{Discussão e conclusão}

Este estudo teve como objetivo analisar a perceção dos/as jovens acerca dos seus percursos de carreira e vivência do processo de autonomização, tendo-se evidenciado as respostas mais salientes tanto em relação aos fatores relativos aos percursos de carreira, como na experiência de acolhimento ou no processo de autonomização.

Em relação aos primeiros, as categorias alternativas de escolha de carreira e autonomia nas decisões escolares, surgiram em muitos dos relatos associadas a confusão, falta de agência na tomada de decisão a nível escolar e também falta de alternativas apresentadas pelo acolhimento. Estes dados parecem apontar para o facto de o acolhimento destes/as jovens não ir ao encontro com o Manual de Boas Práticas proposto por Leandro e colaboradores (2006), que considera fundamental que os jovens em acolhimento residencial possam decidir e fazer escolhas, de modo a promover o seu bem-estar emocional, autonomia e autodeterminação. Estes dados são preocupantes e mostram a importância da formação das equipas das residências de acolhimento em temáticas relacionadas com o desenvolvimento de carreira destes/as jovens, bem como, para a formação dos/as psicólogos/as escolares no que diz respeito à orientação de públicos específicos, como os/as jovens em acolhimento residencial. Relativamente às motivações para a escolha do curso, as respostas foram diversas incluindo motivos como a perceção de facilidade do curso, a identificação pessoal, e a perspetiva temporal (p. ex., não continuarem a reprovar ou atrasar nenhum ano). Quanto ao papel dos estudos antecipava-se, segundo a revisão de literatura e os estudos de Santos (2010), trajetórias menos positivas, onde predominam o desinteresse e o absentismo escolar. No entanto, o papel dos estudos foi uma das categorias mais mencionadas pelos/as jovens, sendo com frequência referidos aspetos como o rendimento escolar, aspirações escolares, a relação com o curso ou estágio que estão a frequentar, mostrando uma valorização da escola na construção dos projetos de vida. Estes aspetos sustentam a ideia do apoio educativo poder ser um ponto de resiliência para estes/as jovens, sendo importante as instituições de acolhimento investirem no apoio aos estudos, proporcionando um ambiente seguro e com os recursos que não teriam no seio familiar.

Os/as jovens referiam ainda nos seus percursos de carreira o papel de pessoas significativas, como a família, amigos e alguns cuidadores. No mesmo sentido, Gonçalves (2013) enfatiza a importância de pessoas significativas que sirvam de modelos para estes/as jovens, considerando que a falta destas se pode refletir na pouca estimulação na construção de objetivos de vida. Sabendo que os valores de vida poderão ter alguma influência na construção de objetivos de vida dos jovens (Gonçalves, 2013), é interessante reparar que os valores de vida mais relatados pelos/as entrevistados/as são muito focados no esforço e/ou entrega pessoal, o que também poderá atuar como fator protetor na construção de um projeto de vida. 
Nos fatores relativos à experiência de acolhimento, os sentimentos experienciados, tanto à entrada como no decorrer da sua vivência em acolhimento residencial, foram uma das categorias mais salientadas, surgindo sentimentos de medo, proteção, tristeza, solidão, injustiça, apoio, aprisionamento, entre outros. Estes sentimentos são coincidentes com os referidos, há dez anos, no estudo dos Percursos de Vida dos Jovens Após a Saída dos Lares de Infância e Juventude (ISS, 2005), caracterizando a experiência de acolhimento residencial como uma experiência plural e tensa. Este aspeto salienta a urgência na reestruturação das casas de acolhimento e do trabalho em torno das experiências de acolhimento ou o reforço de outras medidas tutelares como o acolhimento familiar. Cinco jovens salientaram as aprendizagens feitas na perceção que tinham acerca da sua própria vivência em acolhimento. Todos/ as os/as entrevistados/as consideraram o acolhimento como um local de novas oportunidades, o que está de acordo com os resultados de Rodrigues (2016). Os/as jovens consideraram ainda como positivo no acolhimento as regras, as atividades em tempos livres, a abertura de horizontes e clarificação de objetivos.

Quando os/as jovens foram questionados/as acerca de episódios significativos da vivência em acolhimento, relataram sobretudo memórias de interações familiares, como visitas ou acontecimentos de vida, o que está de acordo com a revisão de literatura que considera que os jovens continuam ligados à família (Siqueira e Dell'Aglio, 2006). Nos fatores mencionados relativos ao processo de autonomização, os/as jovens relataram sentimentos que tinham acerca da saída do acolhimento, tais como a pressão que sentiam relativamente a com quem ficar, o medo de "voltarem à vida antiga", o medo de não conseguirem estabelecer rotinas de estudo quando voltarem para casa, não se sentirem preparados/as para saírem do acolhimento e sentimentos de saudade dos/as colegas e cuidadores/as no acolhimento. Estes relatos refletem a forte ligação com a instituição e a perceção de falta de competências de autonomização. Ao mesmo tempo, os pensamentos dos/as jovens acerca da saída do acolhimento demonstraram um forte desejo em sair para voltarem à família, apoiando mais uma vez as ideias de Siqueira e Dell’Aglio (2006). Apesar de se considerar esta ligação à família como algo benéfico, é importante acompanhar e monitorizar esta fase, de forma a garantir as condições para o jovem estabelecer relações saudáveis com a família de origem. Neste processo é fundamental equipar o jovem com ferramentas de autonomização e autossuficiência, podendo passar pelo ensino de competências de gestão financeira e doméstica, como por exemplo ajudar os jovens na procura de emprego, educação básica, experiência de trabalho e a melhorar as competências profissionais (Silva, Araújo e Taveira, 2011; Silva, Coelho e Taveira, 2017; Gonçalves, 2013; Costa, Tomás, Luís, Rodrigues, Malheiro e Gonçalves, 2015). No que se refere ao planeamento do momento da saída do acolhimento, 
os/as jovens demonstravam a preocupação em sair do acolhimento apenas no fim dos estudos, bem como, aspirações muito focadas na carreira, como por exemplo, entrar na universidade, arranjar emprego, ir trabalhar para fora do país e tirar um novo curso. Estes resultados diferenciam-se dos obtidos nos estudos de Courtney e colaboradores (2001) e Forsman e Vinnerljung (2012), que referem que as expectativas de futuro dos jovens se centram sobretudo em ter uma casa, constituir família e conseguirem uma vida sustentável.

Ao nível das dificuldades antecipadas à saída do acolhimento residencial, os/as jovens referem dificuldades na realização de tarefas de autonomia, tais como alugar uma casa sozinho, criar rotinas de estudo e não conseguirem acabar os estudos, e dificuldades em não conseguirem encontrar um estágio/emprego. Estas preocupações dos jovens alertam para a necessidade, tal como referem Silva, Araújo e Taveira (2011) e Gonçalves (2013), do seu envolvimento em funções típicas da vida adulta.

Por fim, remetendo-nos para os recursos utilizados como meios de apoio no processo de autonomização, foram apontadas as figuras de suporte social, tal como a família, amigos e técnicos/cuidadores, sendo que alguns referiram não terem suporte social. Estas figuras podem atuar como fatores de proteção promovendo caraterísticas de resiliência e desenvolvimento adaptativo (Garmezy, Masten e Tellegen, 1984). Outro recurso percecionado pelos/as jovens na transição para a vida autónoma diz respeito aos apoios estatais, sendo que uns/umas jovens se mostraram mais informados/as que outros. Neste caso, cabe às instituições de acolhimento promover a informação estando preparadas para o esclarecimento aos jovens, sublinhando desta forma as ideias de Ribeiro (2008) que apela à formação especializada dos técnicos que trabalham diretamente com esta população. Ainda no que se refere à categoria dos recursos utilizados no processo de autonomização, a subcategoria mais mencionada foi as competências de adaptabilidade dos jovens. Esta subcategoria está relacionada com a teoria da resiliência abordada por Fergus e Zimmerman (2005), em que os jovens mostraram capacidades em gerar alternativas perante adversidades e/ou abdicar de determinados aspetos em prol dos seus objetivos. Esta capacidade adaptativa é uma das competências de carreira mais referidas para garantir a adaptação e sucesso nas sociedades atuais, estando positivamente correlacionada com a eficácia na procura de emprego (Gamboa, Paixão e Palma, 2014; Guan, Deng, Sun, Wang, Cai, Ye e Li, 2013), sendo portanto um bom preditor do sucesso da autonomização destes/as jovens.

Apesar da riqueza da análise dos discursos recolhidos, é importante refletir sobre algumas limitações. Entre estas sublinha-se a dificuldade de acesso a amostras desta natureza, por indisponibilidade das residências, que se traduziu, neste estudo, num número reduzido de participantes e na escassez de participantes do sexo masculino. Desta forma, seria importante em estudos 
futuros desenvolver estratégias de cooperação que estimulassem uma maior participação das casas de acolhimento e um maior equilíbrio de sujeitos no que respeita ao sexo, considerando ainda importante conseguir chegar a casas de acolhimento de outras zonas geográficas, de forma a obtermos resultados representativos da população em estudo. Seria também interessante fazer-se considerar outras variáveis, no que se refere às diferenças individuais dos jovens de modo a compreender se os discursos dos/as jovens variam de acordo com as mesmas. Ainda assim, consideramos que este estudo poderá servir de base teórica para uma melhoria a nível da intervenção social e educativa, sendo um reflexo da voz dos/as jovens acerca das suas próprias experiências. Esta intervenção deverá atender à estimulação da exploração do mundo do trabalho, do self, e do desempenho de papéis de vida, com o objetivo de criar condições favoráveis para uma tomada de decisão vocacional realista (Silva, Coelho e Taveira, 2017). Uma das conclusões deste estudo centra-se na abordagem do acolhimento residencial como uma oportunidade de vida, considerando que se as condições para o desenvolvimento de competências pessoais e sociais com vista à promoção da autonomia dos/as jovens forem garantidas, é possível ter resultados positivos. No entanto, para a manutenção destes resultados é preciso intervir e acompanhar esta importante transição de vida dos/as jovens. 


\section{Referências bibliográficas}

ANDRADE, Sofia; SANTOS, Paula; COSTA, António, e SOUSA, Dayse (2014), "Bem-estar emocional e implicações: estudo com crianças em acolhimento institucional.”, Indagatio Didactica, 6 (3), 157-174.

BARDIN, Laurence (2013), Análise de Conteúdo. Lisboa, Edições 70.

CARNEIRO, Roberto (2005), Casa Pia de Lisboa - Um projeto de Esperança. Cascais, Principia.

COSTA, Ana; TOMÁS, Catarina; LUÍs, Edson; RODRIGUES, Liliana; MALHEIRO, Mafalda, e GONÇALVES, Serafim (2015), Autonomia: Desafios e práticas no acolhimento de jovens em instituição [Online], disponível em: https:/content.gulbenkian.pt/ wp-content/uploads/2016/05/29202306/Brochura-Autonomia-Final-28_05.pdf.

COURTNEY, Mark; PILIAVIN, Irving, GROGAN.KAYLOR, Andrew, e NESMITH, Ande (2001), "Foster youth transitions to adulthood: A longitudinal view of youth leaving care.", Chil Welfare Leage of America, 80 (6), 685-717.

Decreto-lei no 142/2015 (2015). Proteção de Crianças e Jovens em Perigo. Diário da República I Série A. N ${ }^{\circ} 175$ (15-09-08), 7198-7232.

FERGUS, Stevenson, e ZIMMERMAN, Marc (2005), “Adolescent resilience: A Framework for Understanding Healthy Development in the Face of Risk.", Annual Review of Public Health, 26, 399-419.

FORSMAN, Hilma, e VINNERLJUNG, Bo (2012), "Interventions aiming to improve school achievements of children in out-of-home care: A scoping review.", Children and Youth Services Review, 34 (6), 1084-1091.

GAMBOA, Vítor; PAIXÃO, Olímpio, e PALMA, Ana Isabel (2014), “Adaptabilidade de carreira e autoeficácia na transição para o trabalho: O papel da empregabilidade percebida - estudo com estudantes do ensino superior.”, Revista Portuguesa de Pedagogia, 48 (2), 133-156.

GARMEZY, Norman; MASTEN, Ann, e TELLEGEN, Auke (1984), "The study of stress and competence in children: A building block for developmental psychopathology.", Child Development, 55 (1), 97-111.

GONÇALVES, Sónia (2013), “Jovens Institucionalizados: objetivos e valores de vida.” Master thes., Universidade do Minho.

GUAN, Yanjun; DENG, Hong; SUN, Jiaqing; WANG, Yanan; CAI, Zizun; YE, Lihui, e LI, Yuhui (2013), "Career adaptability, job search self-efficacy and outcomes: A three-wave investigation among Chinese university graduates.", Journal of Vocational Behavior, 83 (3), 561-570.

ISS (2005), Percursos de vida dos jovens após a saída de Lares de Infância e Juventude, Lisboa, ISS.

ISS (2016), CASA 2015 - Relatório de Caracterização Anual da Situação de Acolhimento das Crianças e Jovens, Lisboa, ISS.

LEANDRO, Armando; AlVAREZ, Dora Lameirão; CORDEIRO, Mário, e CARVALHO, Ricardo (2006), Manual de Boas Práticas: um guia para o acolbimento residencial das crianças e jovens, Lisboa, ISS.

RIBEIRO, Anabela Monteiro (2008), "Projeto de promoção de autonomia de crianças e jovens em acolhimento residencial.” Master thes., Instituto Superior de Ciências do Trabalho e da Empresa.

RODRIGUES, Sandra. (2016), "A transição para a vida ativa dos jovens institucionalizados em Casas de Acolhimento - Percursos de inserção.” Master thes., Instituto Superior de Ciências Sociais e Políticas. 
SANTOS, Ana. (2010), “Insucesso escolar de crianças e jovens institucionalizadas.” Master thes., Instituto Superior de Ciências Sociais e Políticas.

SANTOS, Mirela Figueiredo, e BASTOS, Ana Cecília Sousa (2002), "Padrões de interação entre adolescentes e educadores num espaço institucional: resinificando trajetórias de risco.”, Psicologia: Reflexão e Crítica, 15 (1), 45-52.

SILVA, Ana Daniela; ARAÚJO, Alexandra, e TAVEIRA, Maria do Céu (2011), "Tailoring career education and counseling for portuguese foster-youth.”, INTED2011 Conference Proceedings CD, Valência, Espanha.

SILVA, Ana Daniela; COELHO, Petra, e TAVEIRA, Maria do Céu (2017), "Effectiveness of a career intervention for empowerment of institutionalized youth.", Vulnerable Children and Youth Studies, 171- 181.

SIQUEIRA, Aline e DELL'AGLIO, Débora Dalbosco (2006), “O impacto da institucionalização na infância e na adolescência: Uma revisão da literatura.”, Psicologia \&́ sociedade, 18 (1), 71-80.

TAVEIRA, Maria Céu e FARIA, Liliana (2009), “Efeito da Intervenção Psicológica Vocacional na Indecisão e Comportamento Exploratório.”, Psicologia Ciência e Profissão, 29 (3), 558-573.

WANG, Margaret e GORDON, Edmund (1994), Educational resilience in inner-city America: Challenges and prospects, Hillsdale, NJ, Lawrence Erlbaum Associates. 